\title{
Complex Environmental Condition
}

National Cancer Institute

\section{Source}

National Cancer Institute. Complex Environmental Condition. NCI Thesaurus. Code C134028.

Multiple phases with different sets of environmental conditions. 